\title{
CORRESPONDENCIA DE DELMIRA AGUSTINI CON RUBÉN DARÍO, MANUEL UGARTE Y ENRIQUE REYES. PASIONES Y SENSIBILIDADES EN EL NOVECIENTOS URUGUAYO
}

\author{
DELMIRA AGUSTINI'S CORRESPONDENCE WITH RUBÉN DARÍO, \\ MANUEL UGARTE, AND ENRIQUE REYES. PASSIONS AND SENSITIVITIES \\ IN THE URUGUAYAN $1900 S$
}

\author{
Claudio Maíz \\ CONICET-UNIVERSIDAD NACIONAL DE CUYO \\ Argentina \\ cl_maiz@yahoo.com.ar
}

\begin{abstract}
Resumen: En el epistolario de Delmira Agustini analizamos tanto la subjetividad como las conductas socialmente condicionadas del novecientos uruguayo. Agustini mantuvo correspondencia con distintos actores masculinos, nosotros hemos seleccionado a tres de ellos. A partir de los cuales procuraremos una lectura densa que nos permita ampliar nuestra comprensión de los recursos y estrategias que la poeta utiliza de acuerdo con cada uno de los corresponsales. Se toma en cuenta los modelos demográficos que alteraron en cierto modo el lugar de la mujer en la sociedad uruguaya. Los cambios van de la mujer como reproductora del siglo XIX a una mujer con mayores libertades. La propuesta de una lectura no lineal sino densa del epistolario consiste en apelar al recurso de cruzar las cartas que no tuvieron esa disposición al momento de escribirse. De modo que nos permite extraer algunas nuevas interpretaciones de la complejidad de Delmira como sujeto de la escritura.
\end{abstract}

Palabras clave: Delmira Agustini, demografía, modernismo, epistolarios, emociones.

\begin{abstract}
In the correspondence of Delmira Agustini we analyze both the subjectivity and the socially conditioned behaviors of the Uruguayan 1900s hundred. We have selected three from the different male actors Agustini corresponded with. We will attempt a dense reading of such correspondence that allows us to expand our understanding of the resources and strategies that the poet uses according to each one of the correspondents. The demographic models that altered somehow the place of women in the Uruguayan society are taken into account. The changes go from the woman as a reproductive means of the nineteenth century to a woman with greater freedoms. The proposal of a non-linear reading but dense correspondence consists in appeal-
\end{abstract}


ing to the resource of crossing letters that did not have that disposition at the time of writing, so that it allows us to extract some new interpretations of the of Delmira's complexity as a subject of writing.

Keywords: Delmira Agustini, modernism, demography, epistolary, emotions.

Recibido: 15/01/2019. Aceptado: 15/05/2019.

\section{Introducción}

$\mathrm{U}$

no de los objetivos principales de este trabajo es llevar a cabo una lectura densa del epistolario de la poeta uruguaya Delmira Agustini. Entendemos por lectura densa el funcionamiento de dos estrategias de análisis. Por un lado, situarnos entre dos planos, uno de ellos referido a un episodio aciago que no pertenece exclusivamente a la crónica policial, como fue la muerte de Delmira Agustini ${ }^{1}$ a manos del marido, quien luego se suicida. El segundo plano ubica estos episodios de la crónica policial en el contexto político-cultural del Uruguay del 900, en el que rige una determinada economía emocional. El abordaje del epistolario de Delmira propuesto pone énfasis en el "giro afectivo" acaecido en las humanidades y ciencias sociales ${ }^{2}$. Nuestra lectura densa se complementa con una intervención en el orden del archivo epistolar. Es preciso recordar que las cartas son expresiones privadas y destinadas a un corresponsal. La publicidad de la carta es un acontecimiento posterior, generalmente cuando los involucrados ya no viven. Lo dicho implica a personas que han tenido cierta o mucha relevancia en el campo donde se han desenvuelto. Hay varias maneras de intervenir estos documentos epistolares: la omisión, la secuencia temporal, la temática que las reúne. Estas mediaciones son una facultad de quien opera con el archivo epistolar. No obstante, la lectura de un epistolario subordinada a la presentación del recopilador es una entre otras.

\footnotetext{
${ }^{1}$ Nace en Montevideo el 24 de octubre de 1886; publica poesía a partir de los dieciséis años en pequeñas revistas; primer volumen de poemas, El libro blanco (1907); segundo libro, Cantos de la mañana (1910); tercer y último libro editado en vida, Los cálices vacíos, con un pórtico de Rubén Darío (1913). Los astros del abismo se publicará póstumamente, en 1924, con el título de El rosario de Eros. Muere el 6 de julio 1914 a los veintiocho años.

${ }^{2}$ Para un estado de la cuestión v. Lara y Domínguez (2013).
} 
Una vez publicado el epistolario, el lector cuenta también con una cuota de intervención si elige ocuparse de los sentidos diversos que adquieren las relaciones significantes en el interior del epistolario. La matriz epistolar nunca es unívoca sino ambivalente, equívoca, paradojal. El gesto epistolar genera "líneas de fuerzas que orientan el discurso según sus propias leyes". Esa matriz concebida desde la ambigüedad es la incógnita de la epistolaridad (Bouvet, 2006: 65 y ss). Algo más sobre la lectura densa, Fredric Jameson se ha negado a sustraer los fenómenos históricos a una operación de abstracción, que enajena y desfamiliariza el fenómeno, en su lugar propone "una caracterización más global de las secretas afinidades" entre dominios que aparecen como "autónomos e inconexos". Se debe buscar la "secuencia oculta de las cosas" vistas por lo común como aisladas (Jameson, 2002: 58). Una lectura densa del epistolario de Delmira Agustini renuncia a quedar ligada solamente a la cadena conversacional imaginaria determinada por la dualidad presencia/ausencia, propia de este género discursivo. Se busca, por el contrario, develar afinidades que involucren significados de los intercambios producidos tanto en el plano subjetivo como en relación con el contexto. Las cartas siempre son algo más que simples intercambios

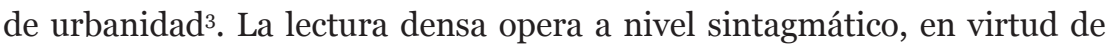
que se altera la cadena secuencial de las cartas, así como también a nivel paradigmático, de acuerdo con la búsqueda de afinidades que enlazan la subjetividad de Agustini con una comunidad emocional. En general, las cartas no solamente han ejercido un papel valioso en los ámbitos de la política o la cultura, sino que han favorecido la construcción de ámbitos afectivos (Bouvet, 2006: 16). El epistolario de Delmira nos permite entonces recuperar estados individuales de afectividad en el marco de las energías emocionales de una comunidad. Por tales razones, a partir del epistolario haremos una clasificación de aquellos estados afectivos que involucran a la poeta en relación con tres hombres (el esposo y dos intelectuales) ${ }^{4}$.

3 "La carta no es sólo una forma textual que permite intercambiar información: además de su contenido, además de lo que 'efectivamente' dice, la carta siempre dice, contemporáneamente, algo más: habla por sí misma, revela el acto de haber sido escrita, testimonia su propio ser en cuanto carta" (Violi, 1987: 91).

${ }^{4}$ Mucho se ha hablado de la mitificación de la vida de la poeta uruguaya a través de su correspondencia. La deconstrucción de dicho mito no obstante puede hacerse no solo gracias al contenido del propio archivo de Agustini sino también al papel que ha jugado por la ficción al imaginar variantes interpretativas de esta trayectoria vital truncada tempra- 
El archivo uruguayo ha revelado que Delmira poseía una casilla de correo o poste restante para recibir su correspondencia secreta, bajo un nombre falso: Lía del Dream, anagrama del nombre Delmira (Larre Borges, 2014: 36). Este detalle de su archivo, entre otros, nos sitúa ante incógnitas sobre los alcances de la conciencia que Delmira habría tenido de su condición de mujer en el interior de la sociedad uruguaya. Se trata de una información ubicada más en el ámbito de lo real-biográfico que de lo mítico. El mito creado en torno de ella, entonces, comienza a deconstruirse a medida que se procesan críticamente estos documentos que nos acercan igualmente a hechos biográficos como creativos. El discurso del yo de Agustini, lejos está de ser mitificador, a pesar de que haya contribuido a la formación de una autoimagen como escritora. La mitificación proviene siempre desde un afuera que moldea discursivamente la figura. En ese sentido, la intimidad del discurso epistolar resulta un suplemento, un plus que no alcanza para descifrar la obra poética ni la subjetividad, sin embargo, aun con estas limitaciones, las cartas de Agustini aportan elementos dignos de considerarse al momento de pensar los temas del erotismo en su obra y en la vida socialemotiva del Uruguay del 900.

Delmira sobreactúa la práctica del secreto en su epistolario, ya que funcionan mecanismos de control, censura o prohibición a su alrededor. Siendo así, si su poesía erótica causaba ciertos sobresaltos en la recatada sociedad burguesa montevideana, qué caso tenía ocultar esa otra faceta de ella en el interior de la escritura epistolar. Lo cierto es que los discursos y las prácticas que se acercaran a la sexualidad y el erotismo no eran tan sencillas de sobrellevar. Desde una visión más global del fin de siglo europeo, Lily Litvak nos habla de un "sistema burgués sexualmente represivo", singularizado "por su hipocresía y su doble escala de valores", de conformidad con ello: "[E]l modelo ideal es el matrimonio y la familia" (Litvak, 1979: 2). Aunque estamos de acuerdo con estas observaciones generales respecto de la "doble escala de valores" y que la estructura familiar admitida es la proveniente del modelo ideal de "matrimonio y familia", el caso urugua-

namente. La vida de Delmira Agustini ha sido ficcionalizada en un intento de desentrañar aquellos aspectos tan misteriosos e inexplicables que tuvo. Algunos casos: Pedro Orgambide, Un amor imprudente (1994); Omar Prego Gadea, Delmira (1996); Guillermo Giucci, Fiera de amor (1995); Adriana Genta, La pecadora, texto teatral. El registro parcial lo ha hecho Beatriz Colombi (1999). 
yo, sin embargo, merece algunas precisiones. En la obra El Uruguay del Novecientos, los historiadores José Barrán y Benjamín Nahun establecen determinados cambios estructurales en el campo de la cultura y la sociedad desde la perspectiva demográfica (1979). Las negociaciones en la consideración del rol de la mujer oscilan entre un "erotismo patriótico reproductivo" (siglo XIX) y una mujer "liberada" de esa carga y compromiso. Las variantes son el resultado de un cambio en el modelo demográfico de la naciente modernidad "periférica" uruguaya. El cambio se produce a través de un disciplinamiento de la sensibilidad "bárbara" procedente del siglo XIX a una que tiene pretensiones de mayor refinamiento, pero también de un mayor control de la fecundidad 5 .

\section{Sensualismo, erotismo y el modelo demográfico}

Los miembros de la generación del 900 uruguayo fueron testigos de un intenso proceso modernizador que se reproducía a lo largo del mundo hispánico. Los cambios político-culturales de la modernización impactaron en la revelación de la sexualidad y el erotismo. Roberto de las Carreras y Julio Herrera y Reissig son dos ejemplos de una actitud transgresora de los modelos de comportamientos eróticos de la sociedad montevideana expresada en la literatura. Se registran tendencias diferentes, como el sensualismo y el erotismo, en la "exaltación del impulso sexual como estrategia liberadora y respuesta creativa" (Giaudrone 13). Una de esas tendencias está representada por José Martí, Julián del Casal, José Asunción Silva, Rubén Darío. Ellos celebran el instinto genésico "como forma de responder creativamente al vacío de la vida y como un desafío al moralismo conservador" (Giaudrone, 2005: 13). Pero el deseo está orientado de "manera fija y unidireccional", esto es, el sujeto masculino orienta el deseo hacia una figura femenina como "objeto pasivo" y simbolizada mediante estereotipos de virtuosidad, agresión o perversidad (Giaudrone, 2005: 13). Esta tendencia

5 "Los respectivos proyectos estéticos de un temprano Carlos Reyes y Roberto de las Carreras incorporan la exploración de la sensualidad, de la perversión y otras formas de sensibilidad excluidas de los modelos decimonónicos de erotismo patriótico reproductivo". Aún más, De las Carreras propone una "politización de la sexualidad” (Giaudrone, 2005: 137). 
disimula el cuerpo en un intento de dominación de la sexualidad, a través de diferentes mascaradas. En la producción modernista del novecientos uruguayo existe una variación al situar el cuerpo en el centro de una poética, "sexualizando la escritura". Así las representaciones eróticas del modernismo-novecentismo uruguayo se sustituyen "por medio de imágenes sexuales que, con frecuencia, y con diferentes resultados, logran invertir los roles tradicionales del sujeto/objeto" (Giaudrone, 2005: 13). Ángel Rama, en el prólogo a Diarios de mi de vida de Rufino Blanco Fombona nos advierte que el fenómeno de una nueva versión femenina y el tratamiento de temáticas erótico-sexuales estaban ausentes en la literatura antes del modernismo. Ahora, ingresan a jugar los debates europeos sobre la mujer que repercuten en América Latina. La interpretación de la mujer y de la relación erótica procede de dos franceses: Rémy de Gourmont y Paul Bourget, cuyas obras fueron verdaderos catecismos para los modernistas hispanoamericanos (Rama, 1991: 20). Una de las primeras secuelas de discusión en torno al decadentismo europeo será la popularidad alcanzada por José María Vargas Vila, como por ejemplo con su novela Ibis (1900). Otros casos que pueden nombrarse son El bachiller (1895) de Amado Nervo, Pasiones (1895) del venezolano José Gil Fortoul. O los textos autobiográficos de Rufino Blanco Fombona, quien supo tratar sus experiencias eróticas con total “decisión y franqueza", algo que no hizo en sus novelas (Rama, 1991: 21).

Desde el punto de vista de un abordaje más denso en el que se conecten particularidades del período y los textos producidos debe considerarse la tesis del historiador José Pedro Barrá, ya mencionada, para quien, en el Uruguay finisecular, la exaltación del impulso erótico chocó con el "disciplinamiento" de la sensibilidad "bárbara" impulsada hacia fines del XIX. Se confrontan dos modelos demográficos que condicionan la sexualidad, el erotismo y los comportamientos matrimoniales en uno y otro momento. Algunos escritores del 900 se sitúan fuera de la norma establecida, ya sea desde la narrativa, el ensayo o la poesía. La figura del Presidente José Batlle y Ordóñez tiene una gravitación especial ya que encabeza el proceso de la modernización del Uruguay, incluyendo políticas más tolerantes hacia las formas del deseo como las expresadas en la literatura de entonces. Carla Giaudrone describe los cambios que se producen en el proceso de modernización: 
A través de la inclusión de un erotismo más explícito, físico y paródico, la escritura del Novecientos uruguayo se distancia del cauto sensualismo que exhibe la primera y más influyente generación de modernistas. La expresión física del deseo sexual en los hispanoamericanos osciló entre la atracción morbosa y la condena a formas no convencionales de percibir el sexo. Con el tiempo, las representaciones de lo perverso, lo corrosivo y cuestionador del cuerpo, cedieron terreno a su reificación, a su transformación en objeto estético. [...] Los respectivos proyectos estéticos de un temprano Carlos Reyles y Roberto de las Carreras incorporan la exploración de la sensualidad, de la perversión y otras formas de sensibilidad excluidas de los modelos decimonónicos de erotismo patriótico reproductivo. (Giaudrone, 2005: 138)

Sin embargo, esta avanzada de renovación estético-ideológica de los escritores del 900 uruguayo tuvo consecuencias fatales para algunos de ellos o su destino final fue un hospicio. Leandro Delgado se ha preguntado si "la extrema libertad y la violencia de esta literatura está vinculada con una represión de las costumbres sociales que se puede considerar igualmente violenta" (Delgado, 2007: 219-221). Otra probable explicación es que existe un desajuste alegórico para el caso de Delmira Agustini en "el proceso de autoinvención en el Uruguay de Batlle”, en el que Enrique Job Reyes, el esposo asesino, encarna un modelo contrapuesto al de Agustini, esto es, el modelo del Uruguay del "antiguo régimen", que no es otro que el del "culto a la fecundidad-maternidad" y también el de la violencia ${ }^{6}$. Mientras tanto la poeta está arrastrada por impulsos renovadores de la política modernizadora y por ende más tolerante de la presidencia de Batlle. Es interesante la tesis de Barrán porque nos permite vincular algunos comportamientos erótico-sexuales con el marco político-cultural del 900. Barrán arguye que

\footnotetext{
${ }^{6}$ Dice Escaja: "El caso resulta particularmente relevante en el Uruguay del 9oo. En su afán de "asombrar al mundo", el gobierno de José Batlle y Ordóñez diseña en gran medida un paraíso artificial con sede en una urbe mínima, apenas industrial: Montevideo. El "antiguo régimen" uruguayo, como califican José Pedro Barrán y Benjamín Nahun a un primer estadio sociohistórico en el que predomina el modelo demográfico de culto a la abundancia y a la reproducción («natural» y rural), será suplantado por un modelo moderno de limitación demográfica que caracterizará y fomentará el régimen batllista ("artificial" y urbano). Este nuevo modelo pretende responder a una realidad moderna de incipiente industrialización que precisa menos pobladores, basando por lo tanto sus necesidades en la «producción» frente a la premisa de «reproducción» propia de las necesidades del primer modelo (Escaja, 2006).
} 
el modelo demográfico del novecientos alteró el lugar de la mujer en la sociedad. La mujer era el máximo "responsable biológico de la fecundidad" que ahora se relativizaba. "La represión de la sexualidad femenina -escribe Barrán - era una condición sine-qua-non [sic] para que triunfara el control de la natalidad con métodos predominantemente espontáneos, no artificiales" (Barrán y Nahun, 1979: 68). De acuerdo con el funcionamiento de este modelo, en el novecientos uruguayo (como en otras partes de América) se produce un auge de la llamada "histeria", de las "enfermedades nerviosas", dolencias que afectaban a las mujeres, al igual que "jaquecas", “insomnios" (Barrán y Nahun, 1979: 69). Así, por ejemplo, Delmira en una carta que le escribe a Rubén Darío le dice: "Perdón si lo molesto una vez más. Hoy he logrado un momento de calma en mi eterna exaltación dolorosa [...] Y no sé si su neurastenia ha alcanzado nunca el grado de la mía" (Agustini, 2006: 65, subrayado nuestro). Esta enfermedad nerviosa caracterizada por la depresión podría ser una consecuencia fisiológica al hecho de que se acentúa el culto a la virginidad en reemplazo de la función fecundadora femenina del modelo demográfico anterior. A todo ello se sumaba que los matrimonios se llevaban a cabo a edades más tardías (Barrán y Nahun, 1979: 69). Las mujeres eran culpadas por el exceso de fecundidad en el modelo demográfico del siglo XIX. Más que el sexo, estaba en cuestión, de acuerdo con Barrán, la fecundidad (Barrán y Nahun, 1979: 74). En el 900 quedaban dos caminos o la independencia económica o el matrimonio. Ninguno de estos caminos pudo cumplirse satisfactoriamente en Delmira. ¿Con qué alternativas contaba?

\section{El epistolario: otra posible lectura}

En este trabajo hemos tomado el epistolario reunido por Idea Vilariño bajo el título de Cartas de Amor. No todas las cartas son de amor, por lo tanto, el título parece un poco abusivo en ese sentido. Quizás si en lugar de amor, el título hubiera contenido la palabra emoción o sentimiento habría dado mejores pistas sobre su contenido. Aunque la mayor parte de las cartas están ocupadas por el sentimiento amoroso, ya de manera lúdica, seria o elevada. Sin embargo, hay corresponsales que no entran en la categoría amorosa. El conjunto de cartas reúne las que Agustini le escribió a Enrique Job Re- 
yes, quien luego se convertiría en su esposo-asesino; las de Manuel Ugarte, Rubén Darío, Alberto Zum Felde, Roberto de las Carreras y un apartado titulado "Correspondencia íntima con otros pretendientes". Asimismo, cartas de corresponsales desconocidos, una de "Manino" y otra de un tal "Edipo”. El orden del epistolario se rige más por los temas y corresponsales que por una secuencia cronológica. Las verdaderas correspondencias (entendidas como la carta a un destinatario y su respuesta) se cumplen con Rubén Darío y Manuel Ugarte. Del resto tan solo se conservan las cartas de quienes escribieron a Delmira. Esto significa que conocemos las voces de esos corresponsales, pero no la de Agustini al dar su réplica. Con la correspondencia mantenida con Reyes ocurre algo muy particular, ya que el fenómeno se produce a la inversa, es decir, se conservan las cartas de Delmira durante su periodo de noviazgo, no sabemos si todas. De estas cartas pertenecientes a la poeta se logra inferir parte del contenido del diálogo que entablan los novios. Con todo, se conserva una sola carta de Reyes que guarda un interés particular, por varios motivos de los que nos ocuparemos.

Como ya lo adelantáramos, nuestra propuesta consiste en trazar otros recorridos de lectura (con vistas a esa incursión densa del epistolario) por medio del cruce de las cartas a fin de reconfigurar la significación del epistolario considerando las filtraciones de su contexto socio-afectivo. Parece ser altamente productivo emprender este cruce de las cartas, en primer lugar, porque al escribirse cada una de ellas ninguna coexistió con otra. No podía ser de otra manera ya que la garantía de confiabilidad de quienes las recibieron o escribieron descansaba en el pacto que rige estos discursos, refrendados por artefactos tales como el sobre, el lacre, la entrega tercerizada. El epistolario de Delmira se caracteriza por una disposición cronológica imprecisa por momentos (Delmira no fechaba sus cartas); por una escasa o nula información sobre los lugares de emisión; por la ausencia de las respuestas a todas las cartas. Este conjunto de realidades irrevocables hace necesario buscar una sistematización alternativa desde perspectivas que obliguen a leer los textos ya no como cartas subordinadas al pacto de confiabilidad sino como documentos que pueden interceptarse, contradecirse o ampliar el conocimiento de los corresponsales, incluyendo principalmente a Delmira. El resultado esperado sería lograr la conexión de aquellos planos de escritura epistolar desplegados a partir de estados emocionales con el espesor sociocultural uruguayo. 
En consecuencia, un primer paso sería declarar que nos ocupamos de cartas que ella escribió a tres hombres (entre otros): Reyes, Ugarte y Darío. En segundo lugar, proponer un recorrido conforme a los estados emocionales de Delmira, a saber: un estado amoroso convencional que practica con su novio; el rapto pasional con Manuel Ugarte; la tristeza, congoja y angustia que le confiesa a Rubén Darío. Por lo tanto, habría tres estrategias epistolares que se perciben y varían de acuerdo con el interlocutor. A todo esto, se sumaría una cuarta comunicación epistolar que no pertenece a Delmira, pero la involucra no solamente desde la escritura (por estar dirigida a ella) sino, por la naturaleza perlocutiva que anima este texto, como víctima de las determinantes culturales del 900 que la llevarían a la muerte. Se trata de la carta de su exmarido, que expresa otra emoción, en este caso, la emoción violenta.

\section{La carta del exmarido en una ciudad violenta: el "crimen pasional"}

Habíamos adelantado detenernos antes que nada en la carta de Reyes, al parecer la única que pudo eludir el vendaval destructivo de la madre después de la muerte de Delmira7 ${ }^{7}$. A partir de la única que se preserva de Reyes se deducen varios componentes de su personalidad, sin pretender llevar a cabo un análisis psicológico, pero también de su subjetividad como representativa de una dominante cultural rigurosamente masculina de comienzos del siglo XX rioplatense. La carta de Reyes es la muestra del espesor cultural del Montevideo de entonces, que se caracteriza por un modelo re-

\footnotetext{
${ }^{7}$ Circunstancia que se repite con las cartas de Delmira a Ugarte, pues algunas de ellas fueron destruidas por su esposa en un arrebato de celos. Ugarte debió dejar a un amigo suyo la petición de que se dieran a conocer una vez muerto. Esos papeles fueron dejados a su amigo Hugo Barbagelata. Su testimonio confirma la relación Ugarte-Agustini: "Yo sé que el rápido idilio Agustini-Ugarte trascendió al público rioplatense [...] Son éstas, a mi entender documentos valiosos, para el estudio psicológico que deberá hacerse algún un día de aquella mujer genial [...] En la primera , siempre sin fecha, según su costumbre, en común papel de carta [...] llenó nuestra autora tres carillas en las que parece hubiera querido volcar toda su sinceridad y el orgullo de mujer ya vencida, entregada a un destino cuyo fin ignoraba. [...] En la segunda carta que poseo, en raro papel crema japonés, de exóticos paisajes [...] dio fin la Agustini, supongo, a una correspondencia sólo en parte conocida por sus padres" (Barbagelata, 1953: 301-304).
} 
lacional heterosexual de dominación masculina que condicionaba las conductas de las parejas en vías de constituir una familia.

En general en las lecturas del epistolario de Delmira con Reyes se ha producido una desvalorización de las cartas por el hecho de que Delmira se ocupa de trivialidades, propias de una joven en trato con su novio y se motivan cuando ella o él se ausentan. Se inicia en 1908 debido a un viaje de Delmira a Buenos Aires. Es cierto que las cartas que se conservan pertenecen a Delmira, salvo la que habremos de citar y cuya autoría es de Reyes. En resumen, hay una cantidad considerable de cartas de la poeta a Reyes, pero se ha preservado una del exmarido que resulta de sumo interés para nuestros objetivos. La carta de Enrique Reyes pertenece al momento posterior a la separación de la pareja. No es difícil de suponer que el destino trágico de Delmira se anuncia en esta carta. Es el anticipo de lo que se ha conocido como un "crimen pasional", en un contexto de violencia rioplatense (duelos, suicidios, opresiones de clase y raza) ${ }^{8}$. Vale la pena realizar una breve alusión al denominado "crimen pasional", aunque, desde una mirada antropo-sociológica e histórica. ¿Cuáles son los componentes de aquel contexto de "crimen pasional"? Contiene tres unidades primarias: el vínculo amoroso; la emoción; la ruptura violenta (Jimeno, 2004: 24). Componentes que están presentes en la crónica de la muerte de Delmira. El ordenamiento jurídico ha sostenido que la intensa emoción recubre la acción por lo tanto hace excusable o por lo menos aminora la pena del crimen. Desde el punto vista antropo-sociológico ello es el resultado de una larguísima tradición que ha puesto la emoción como la sombra y hasta la negación de la razón (Jimeno, 2004: 24).

Hasta mis oídos - escribe Reyes - ha llegado la noticia de que tú quieres manchar mi nombre, que hoy es el tuyo, pues también lo llevas, con una calumnia. Si tal cosa hicieras, que no lo creeré jamás, yo sabría lavar la mancha arrojada sobre mi honor, con la sangre inocente de nuestras vidas. Y ése sería el castigo para aquella que, el día de nuestro casa-

\footnotetext{
${ }^{8}$ Escribe Jimeno que en América Latina aconteció un "proceso de instauración de las nuevas formas de subjetividad" en las que se fusionaron "conflicto, emoción, violencia y crimen como si fuera una única entidad destructiva". (Jimeno, 2004: 29) La incivilidad como amenaza de la sociedad civil ya está presente en la literatura latinoamericana desde el Facundo (1845) de Domingo Sarmiento. Esa incivilidad es homologable a una emocionalidad incontrolada, precisamente por la ausencia de una educación que las module.
} 
miento, en una entrevista que tuvimos en la sala [...] llegó a hacerme revelaciones monstruosas de impureza y deshonor [...] (Agustini, 2006: 44, énfasis nuestro)

De esta manera comienza la carta de Enrique Reyes dirigida a Delmira. Es una carta amenazante pero correctamente escrita, lo que en cierto modo desbarata la idea de un Reyes inculto, aunque nunca llegara a comprender

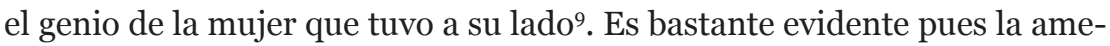
naza de muerte y de posterior suicidio que hay en sus palabras. La violencia del lenguaje está motivada no en un estado de "emoción violenta”, sino que obedece fríamente a los códigos del honor a los que Reyes está sujeto, no de manera aislada o descontextualizada. La emoción en esta circunstancia no es un estado exclusivo de la conciencia sino un mensaje emotivo conformado según los términos de una "relación contextualmente codificada” (Jimeno, 2004: 31). Al fin de cuentas la manifestación emocional sería "una verbalización de patrones culturales" para el intercambio de mensajes (Jimeno, 2004: 31). Es necesario recuperar la dimensión cultural de la vida emocional, en el sentido de que los intercambios no se dan a través de individuos sino de sentidos socialmente compartidos. Continúa Reyes:

[...] aquella noche en que quisiste ser mía y que yo me negué diciendo que jamás haría eso sin que primero fueras mía ante la ley y ante Dios. [...] jamás mancharía tu nombre y tu honor, cediendo a fogosidades de tu temperamento. [refiriéndose a la madre de Delmira] Yo sabré defenderme de esa calumnia infame. Y si ella llegara a manchar mi nombre en lo más mínimo, te lo repito nuevamente, sabré lavar la mancha con sangre, sangre que irá a salpicar el alma perversa de la autora de nuestra desgracia. (Agustini, 2006: 45 énfasis nuestro)

Como se puede observar en ambas citas aparecen las palabras "lavar" y "sangre”. Lavar el honor es limpiar un linaje (Parker, 1999) (Salinas, 1996) (Pitt-Rivers, 1979). Además de las referencias a la ley y a Dios que son los principios a los que apela para condenar, en última instancia, la "fogosidad

${ }^{9}$ Manuel Ugarte en un artículo de los años cuarenta recuerda haber escuchado de Reyes estas palabras. "Yo me encargaré nos dijo de romper los devaneos y de alejarla de toda preocupación intelectual. Es una mujer como las otras. La poesía y el piano son entretenimientos de soltera, sin ninguna significación" (Ugarte, 1943). 
del temperamento" de su novia. Ella ocupa el lugar de la mujer que es incapaz de refrenar sus impulsos eróticos; la conducta de Reyes no hace sino resguardar el honor y el buen nombre de ella. Paternalismo e hipocresía son caras de una misma moneda en el comportamiento masculino que tenía permitido satisfacer el "temperamento fogoso" gracias a la prostitución. La conducta individual de Delmira, a pesar de lo dicho, es el resultado de un desplazamiento en relación con los mandatos sociales patriarcales y heterobinarios. La uruguaya emprende una trayectoria vital de reafirmación de una dimensión más colmada de lo femenino en un contexto de dominación masculina arraigada. Al decir de Ana Inés Larre Borges: "Como les ocurrió a otras mujeres poetas del fin de siglo hispanoamericano, Delmira debió enfrentar una tradición masculina con el paradójico instrumental provisto por esa misma tradición” (Larre Borges, 2014:38). La poeta estaba inserta en una compleja red compuesta de las representaciones de la vida sentimental y la emoción como negación de la razón; los sistemas morales, las clasificaciones y las relaciones de género; la pasión y la violencia como reductos de incivilidad, a veces ligada a la posición social (Jimeno. 2004: 30). El resultado del juego de estos factores no podía ser otro que la muerte, que no estaría motivada en la "ofensa" al honor de Reyes, sino propiciada por la misma Delmira al carecer de otros recursos que no fueran los que el horizonte socio-cultural le deparaba ${ }^{10}$.

Arturo Visca propone algunas conjeturas para explicar la separación y luego el fatal desenlace, mediante algunos testimonios "que sirven para hacer ver la complejidad psicológica de la poetisa” de acuerdo con la presencia de otros hombres en su vida. Entre ellas y a modo de ejemplo, la relación sentimental con Manuel Ugarte, probada en la correspondencia que mantuvieron. Delmira Agustini contrae enlace con Enrique Job Reyes, pero como lo muestra el epistolario se siente pasionalmente atraída por Manuel Ugarte. O la existencia de una carta de Ricardo Más de Ayala, cono-

${ }^{10}$ Manuel Ugarte escribe unas memorias tituladas Escritores iberoamericanos del novecientos (1947). En este texto se refiere a la muerte de Delmira como alguien que fue "sacrificada en Montevideo por su marido" (Ugarte: 23). En realidad esta alusión a la poeta hay que enmarcarla en una visión amarga de la generación del 900, pues fue una "generación vencida", ya sea porque la mayoría de ellos murió prematuramente, otros sufrieron la pobreza, hicieron una obra fragmentaria, algunos estuvieron expatriados. En suma, "ninguno fue feliz, ninguno alcanzó la paz propicia que ayuda a emprender la obra verdaderamente durable" (Ugarte, 1947: 11). 
cido donjuanesco montevideano, quien fuera señalado en algunas crónicas periodísticas (Crítica del 7/VII/1914) como el causante de la tragedia final. Según Visca, existe un "intrincado laberinto de relaciones amorosas" en la vida de Delmira que prueban "la complejidad psicológica de la poetisa". El crítico uruguayo traza algunas vinculaciones entre la "personalidad humana de la poetisa y su creación lírica", admitiendo que en ella habitaban "dos personalidades casi incomunicables entre sí: por un lado, la de una señorita ingenua y que llevaba una vida apaciblemente burguesa ajena a toda vivencia intensa de lo erótico". Agrega que ella era incapaz de comprender su poesía erótica. Esta presunción, que será germen de fallidas interpretaciones, abreva en un juicio que emitió Vaz Ferreira al decir que era un "milagro" la poesía de Delmira y que ella misma no era capaz de entender plenamente su producción poética ${ }^{11}$. El mito de la sublimación ha sido impugnado por la crítica feminista y con toda razón ${ }^{12}$.

Visca concluye que en el mundo lírico-erótico queda claro "la autenticidad de su creación poética, con profundas raíces vitales asumidas lúcidamente". Finalmente, el crítico se muestra a favor de destruir "el mito de la niña ingenua" que se ha prestado a tantos equívocos (Visca, 1979). Desde este entramado de procedencias sociales y de conductas condicionadas debe pensarse la trágica muerte de Delmira.

\section{Estados emocionales del Epistolario}

Como dijimos anteriormente, el epistolario admitía varias operaciones de lectura. En primer lugar, un reordenamiento de acuerdo con los estados

${ }^{11}$ En 1907 aparece El libro blanco, en él Vaz Ferreira dice: "Si hubiera de expresar con un criterio relativo, teniendo en cuenta su edad, etc., calificaría su libro sencillamente como un milagro. Usted no debería ser capaz, no precisamente de escribir, sino de entender su libro. Como ha llegado usted, sea a saber, sea a sentir, lo que ha puesto en ciertas páginas, es algo completamente inexplicable" (cit. Silva, 1968: 30).

${ }^{12}$ La revisión crítica feminista ha venido de trabajos pertenecientes a Girón Alvarado (1995), Giaudrone (2005), Escaja (2006), García Gutiérrez (2013), entre otras autoras. Si bien esta corriente ha discutido el canon masculino del modernismo, la mitificación de la autora, los enfoques biografistas para nombrar alguno de los problemas que otra orientación crítica no había considerado, nuestro trabajo está centrado en las cartas de Delmira, por lo tanto nuestros recursos metodológicos han sido otros, provenientes de la sociología y la antropología literaria. 
emocionales de Delmira. También un cruce de cartas de coexistencia imposible hasta que llegan a integrar un epistolario. Estas variantes lectoras se enriquecen además si logramos trazar los vínculos entre paradigmas heteronormativos en el contexto del Uruguay del 900 y las estrategias discursivas de los textos. Hay un estado amoroso que podemos calificarlo de convencional. Delmira Agustini vive su noviazgo de acuerdo con los parámetros de la época. Las visitas del novio a la casa, algunas salidas, asistencia a eventos públicos; todo ello bajo la supervisión de la madre. Ya hemos dicho el escaso valor que se le atribuye a las cartas que ella le escribió a Enrique Job Reyes, no sin razón dado la irrelevancia del contenido de tales cartas $^{13}$. Pero lo interesante de ellas desde luego no está en el contenido, sino en algunas estrategias discursivas que Delmira utiliza en ese intercambio epistolar. Estas estrategias discursivas obedecen, a nuestro juicio, a ciertos comportamientos de la poeta y nos brindan alguna información adicional sobre su personalidad en el contexto cultural al que pertenece, como hemos venido sosteniendo. Las cartas a Reyes encierran alguna relevancia entonces por los gestos (o poses) que Delmira adopta (Molloy, 2017). En principio serían dos las que merecen destacarse. La primera tiene que ver con la existencia de una "correspondencia secreta" de Delmira. Idea Vilariño, al momento de explicar estos secretos dice no creerle demasiado. Delmira además habla de un "peligro" en el intercambio epistolar, por eso le encarece a su novio que extreme los cuidados. Estas dos circunstancias para Vilariño significan que Delmira está "dramatizando". La dramatización procura quizás ponerle algún contorno más excitante a la actuación femenina que desde todo punto de vista es tan estereotipada como condicionada socialmente.

Este procedimiento constituye una escenificación que contiene el cumplimiento de diferentes papeles, algunos con clara identidad y otros a través de enmascaramientos; una supuesta correspondencia secreta; la mención del "peligro" frente a un supuesto control materno. Ya lo había visto hace tiempo Rodríguez Monegal cuando hablaba de la incompatibilidad entre el personaje la "Nena" que Delmira representaba en su casa y la "pitonisa" que escribía en "pleno delirio". Ella firmaba las cartas como la Nena

\footnotetext{
13 "Estas cartas entre Delmira y Reyes son las más, pero dicen poco, a menudo, nada: seguridades, reproches, mensajes insignificantes" (Vilariño, 2006: 6).
} 
mientras producía una poesía muy lejos de una etapa infantil. Son seis los años que van de El libro blanco a Los cálices vacíos, muchos de los cuales coincidieron con las cartas enviadas a Reyes en tono infantil. Dice el crítico uruguayo: "La Nena era la máscara con la que circulaba la pitonisa por el mundo; era la máscara adoptada como solución al conflicto familiar que le imponía sobre todo una madre neurótica, posesiva y dominante" (Rodríguez Monegal, 1969: 41). Estamos de acuerdo con el uso de la máscara ${ }^{14}$ en la escenificación de las cartas, pero Delmira no se siente atemorizada por la madre que, como vimos, para Vilariño es una "dramatización" que la poeta crea. Delmira actúa ante sí misma o pone en movimiento una pose.

La crítica coincide en este uso de la máscara. Aunque la máscara supone la representación de un personaje, con lo cual estaríamos frente a una interpretación psicológica de la poeta. A pesar de que esto es admisible, podríamos incursionar un poco más allá, con lo cual es preciso articular el concepto de palabra con el de escritura desde la perspectiva del psicoanálisis y su identidad como escritora. Los pliegues de Delmira se constatan en muchas de las cartas escritas a Reyes. Hay dos que se intercambiaron y son las únicas en todo el epistolario Reyes-Agustini que se alude a la poesía, aunque como se verá de una manera probablemente bastante irónica. En una carta muy breve de fecha 6 de junio, Delmira dice: "Recibo recién su carta. Resúltanme esos versos los más verdaderos que se hayan escrito nunca..." (Agustini, 2006:16). Los "versos" que le ha escrito Reyes en una postal enviada al comienzo del noviazgo son los siguientes: "Hacia ti Nena encantadora / Va mi alma que te adora" (Agustini, 2006:19). Presumimos que Delmira a esa altura de su sensibilidad poética no habrá encontrado otro elogio para estos "versos" más que calificarlos de "verdaderos" ya que no podían despertar ninguna otra reacción estética. La idea de "verdad" es posible leerla desde un gesto irónico.

\section{La puerilidad: la máscara como estrategia}

A continuación queremos mostrar algunas formas de comunicación episto-

\footnotetext{
${ }^{14}$ Un trabajo más reciente retoma la temática, aunque con una perspectiva crítica proveniente de los estudios feministas (Varas, 2002).
} 
lar de Delmira Agustina a Enrique Reyes, que tiene como rasgo particular un estado de puerilización. Dicho estado se trata de un enmascaramiento, utilizado como estrategia que desvíe el centro de atención y le permita ensanchar las vivencias subjetivas en soledad. En este sentido es interesante lo que Ugarte le escribe en una carta dirigida a Delmira: "Y que la tinta no sirva de antifaz" (Agustini, 2006: 55). ¿Sospechaba el argentino que la uruguaya podía no ser del todo sincera? Veremos en el análisis de la correspondencia Ugarte-Agustini la manera como se zanja este pedido. De momento, podríamos interrogarnos por las razones de la elección de la máscara pueril en estas cartas, aunque no vayamos a obtener más que respuestas conjeturales. Sería factible quedarse con la versión más sencilla de que esta acción expresiva responde a una manera particular de tratamiento entre novios, la creación de un código para ejercitar una vinculación menos formal. Es seguro que ese es un nivel del asunto. Pero no puede conformarnos dado que de manera paralela el yo que actúa ser una niña está produciendo la primera gran poesía erótica de América Latina. Estas incógnitas entonces corresponden al orden de la identidad, la escritura y la elección consciente o no de la etapa de niñez como patrón comunicativo. Si de ella brotaba tanta energía pulsional expresada en su poesía ¿por qué no haberla continuado en las cartas? ¿Qué lleva a ese cambio tan brusco y contrastante? Además, si establecemos una comparación con el tipo de escritura de otras cartas, como las enviadas a Manuel Ugarte o Rubén Darío, se demuestra la altura que es capaz de alcanzar en su comunicación epistolar.

Dijimos que en este contexto enunciativo nos topábamos también con cuestiones atinentes a la identidad. Una referencia ineludible a ello es el cambio en la persona gramatical, esto es, de la primera a la tercera, que utiliza en diversas cartas o que combina en una sola. Por ejemplo: "Así que la Nena se quedó muy furiosa", "La Nena sigue hoy muy mejorcita gracias a Dios"; "Puede usted creer que toda la fiesta de la Nena era pura bromita". Para mayor abundamiento, en el pacto de fiabilidad de la carta la firma resulta un dispositivo importante. Delmira desplaza constantemente la identidad de la firma. El resultado de este mecanismo es una identidad flotante, inestable. Las primeras cartas las firma con una "N.", luego como "Nena", "Delmira" o "Yo". Hay cartas en las que firma "Delmira, Nena, Yo". Todo esto está vinculado con el tratamiento a su novio. Lo llama al comienzo del epistolario “Sr. Enrique J. Reyes”, luego solamente "Enrique”, para alter- 
nar luego estos apelativos: "Pototo", "Quique", "Papito" o "mi viejo". En el trato también hay lugar para introducción de los posesivos "Quique mío", "de Yo", “de Delmira”, "de la Nena".

\section{Figuras emblemáticas. El rapto pasional con Manuel Ugarte}

En el epistolario de Delmira existe una correspondencia corta pero intensa con Manuel Ugarte, que se enriquece con fotos enviadas por él y un dibujo que hiciera Delmira del ensayista argentino. En la trágica muerte de la poeta uruguaya, Manuel Ugarte juega un papel muy importante en tanto objeto de deseo de Agustini. Larre Borges ha intentado restituir a Ugarte al centro de la escena del drama de la poeta uruguaya (2006). Por lo que las cartas entre ambos son de gran valor, puesto que complementan la escenificación de la tragedia que se avecina, es decir la muerte violenta de Delmira.

La correspondencia Agustini-Ugarte es amorosa. De acuerdo con Patrizia Violi, en la tradición epistolar, "la carta siempre ha sido sobre todo carta de amor" (Violi , 1987: 97). Al ser esta correspondencia de tipo amorosa, estaríamos entonces ante la forma de la estructura epistolar más auténtica. Continúa Violi: "Porque el amor, o mejor dicho la expresión del amor [...] se basa bastante más sobre la ausencia que sobre la presencia. Para hacerse palabra, el amor requiere una distancia, una ausencia: la felicidad no se cuenta, se vive; sólo el deseo puede decirse" (Violi, 1987: 97). La expresión del deseo por parte de Delmira, motivada por la ausencia de Ugarte, es lo que más se destaca en este acotado intercambio de cartas: "[...] prefiero el sueño de lo que pudo ser a todas las realidades en que V. no vibre" (Agustini, 2006: 57). Ugarte también comprende el efecto de la ausencia cuando le escribe: "Proyecte a distancia con las letras su palabra franca y su mirada azul" (Agustini, 2006: 55, subrayado nuestro). El contenido pasional de las cartas se eleva como la de algunos de sus poemas. "Déjeme creer -escribe Delmira- que volverá algún día. Que será pronto. Y perdone a mi alma si lo quiere más que en la púrpura hiriente de los triunfadores, en el luto adorable de los injustamente vencidos [...] Mis manos en las suyas" (Agustini, 2006: 54). En otra carta Delmira desconoce si Ugarte ha recibido una anterior y se lo pregunta. Luego agrega: "Conste que sólo quiero tranquilizarme 
acerca del destino de un pétalo arrancado a mi alma para la garra felina de su espíritu..." (Agustini, 2006: 55). El deseo se expresa en la escritura cuando sobreviene la ausencia:

V. sin saberlo sacudió mi vida. Yo pude decirle que todo esto era en mí nuevo, terrible y delicioso. Yo no esperaba nada, yo no podía esperar nada que no fuera amargo de este sentimiento, y la voluptuosidad más fuerte de mi vida ha sido hundirme en él. Yo sabía que V. venía para irse dejándome la tristeza del recuerdo y nada más. (Agustini, 2006: 57)

El escritor argentino estuvo muy cercano a la boda de Delmira, a punto tal de ser testigo junto con Juan Zorrilla de San Martín. En 1943 Ugarte cuenta detalles de este episodio en una nota publicada en una revista de Montevideo (Ugarte, 1943b: 120). En ese texto la recuerda con palabras muy laudatorias, dándole el título de "la poetisa más grande que ha producido Uruguay". Agrega que sobre ella "parecieron dejar caer los dioses todos sus tesoros: la belleza extraordinaria, la sensibilidad vibrante, el talento sin igual" (Ugarte, 1943b: 120). También Ugarte con el tiempo advierte que una aguda contradicción produjo el desenlace fatal: "Había nacido para encantar. A toda costa quisieron hacer de ella, sin embargo, una tranquila dueña de casa con muchos hijos". Aquí tenemos el ejemplo del modelo demográfico ya señalado, pero no el de la modernización, sino el del siglo XIX, es decir, la mujer reproductora. Atribuye a sus padres parte de esta responsabilidad al pretender resolver "lo excepcional dentro de lo ordinario [...] encerrar un alma desorbitada [...] en los moldes exiguos de la costumbre y de las convenciones sociales" (Ugarte, 1943b: 120). A propósito del casamiento, Delmira le confiesa a Ugarte la manera cómo lo vivió luego que se ha separado de Reyes:

[...] yo debí decirle que V. hizo, el tormento de mi noche de bodas y de mi absurda luna de miel [...] Lo que yo sufrí aquella noche no podré decírselo nunca. Entré a la sala como a un sepulcro sin más consuelo que pensar que lo vería. Mientras me vestían pregunté no sé cuántas veces si había llegado. Podría contarle todos mis gestos de aquella noche. La única mirada consciente que tuve, el único saludo inoportuno que inicié fueron para $\mathrm{V}$. Tuve un relámpago de felicidad. Me parecía un momento que V. me miraba y me comprendía. Que su espíritu estaba bien cerca del mío entre toda aquella gente molesta. Después, entre besos y salu- 
dos, lo único que yo esperaba era su mano. Lo único que yo deseaba era tenerle cerca un momento. El momento del retrato... y después sufrir, sufrir hasta que me despedí de V. Y después, sufrir más, sufrir lo indecible [...] (Agustini, 2006: 56)

Agustini padece de una incapacidad de aceptar el destino familiar como una imposición socialmente determinada. Circunstancia que la atormenta, le dice en carta a Darío: "A mediados de octubre pienso internar mi neurosis en un sanatorio, de dónde (sic), bien o mal, saldré en noviembre o diciembre para casarme. He resuelto arrojarme al abismo medroso del casamiento" (Agustini, 2006: 66, subrayado nuestro). Para sopesar la densidad de la Delmira-sujeto hay que recurrir nuevamente al epistolario con Reyes, a la sazón el novio con quien se iba a casar. En una de las últimas cartas del epistolario, Delmira le escribe: "Paréceme que hay en tu amor yo no sé qué nube de tristeza, de desesperanza que yo quisiera borrar. No me dudes nunca, mi vida nunca!... Duda de todos del mundo, de la Vida, de todo! Antes de que tu Nena" (Agustini, 2006: 41). En el billete que le deja a Reyes al abandonarlo: "Te jura aquella que te quiso tanto y que hoy se aleja de ti impulsada por el destino que es invariable" (Agustini, 2006: 43, cursiva del texto). El tono trágico e irreversible que utiliza es probable que se comprenda mejor en las confesiones que le hará a Rubén Darío en sus cartas.

\section{El otro emblema. Rubén Darío y la Agustini sufriente}

Delmira Agustini conoce a Rubén Darío en 1912, cuando éste viaja por América como director de la revista Mundial ${ }^{15}$. Como consecuencia se da un intercambio epistolar, "interesante por lo que revela de la actitud de uno y otro, o más bien de uno ante otro", al decir de Silvia Molloy (1983: 15). Las cartas que intercambia con Rubén Darío constituyen un ámbito en el que Agustini descubre los padecimientos devenidos de un conjunto de contradicciones en las que ha debido de vivir. La "eterna" Nena y la

${ }^{15}$ Darío no fue solamente un confesor en la relación que mantuvo con Delmira Agustini. Para ella es la figura señera que busca para disputar su espacio de reconocimiento artístico (v. García Gutiérrez, 2016/2017). 
poeta ardiente, la pasión por Ugarte y un adocenado matrimonio, la joven burguesa y una sociedad que no le deja otro papel, las máscaras utilizadas y los desbordes eróticos son algunos de esos pares opuestos. La diferencia de edad, la admiración que siente por el gran poeta de América, entre otras razones, hacen que Agustini se sitúe en una posición subordinada en el intercambio epistolar respecto de Darío. Las pocas cartas intercambiadas nos sirven para confirmar muchas de las presunciones que nos habíamos hecho, en especial a lo que Visca, desde una perspectiva psicologista, denomina las tres personalidades de la poeta: "una personalidad social" (superficial, de apariencias y máscaras), la personalidad de un "yo profundo" (riqueza interior y experiencia amorosa) y "la personalidad poética" (convierte en creación las experiencias de la segunda personalidad) (Visca, 1979: 10 $)^{16}$. Estaríamos en condiciones de decir que el contenido de las cartas a Rubén Darío es el desenvolvimiento emocional de quien experimenta tantas contradicciones como desdoblamientos y que llegado a un punto se tornan intolerables. Escribe en una primera carta: "Hoy he logrado un momento de calma en mi exaltación dolorosa” (Agustini, 2006: 65). Es evidente que el dolor la compele a revelar sus padecimientos: "Y estas son mis horas más tristes" (Agustini, 2006: 65). Pero estas intimidades confiadas a Darío permiten echar luz asimismo sobre la percepción que tiene sobre su vida. En esos estados que le trasmite a Darío, Delmira llega a lo que ella llama "la conciencia de mi inconciencia"; mirar "la locura cara a cara" y lo más relevante es haber luchado con esa locura "en la soledad angustiosa de un espíritu hermético" (Agustini, 2006: 65). Su lucidez impresiona, escribe: "No hay, no puede haber sensación más horrible. Y el ansia, el ansia inmensa de pedir socorro contra todo - contra el mismo Yo, sobre todo- a

${ }^{16}$ Sin embargo, habría que tener en cuenta lo opinión de Silvia Molloy respecto a que estamos frente a una escritora con todo lo que ello conlleva: "Algún día habría que analizar con detenimiento el cuidado, la energía que dedican ciertos escritores a construir su imagen, a fabricar - a aderezar- su persona. El problema es interesante, no sólo por lo que revela del escritor o de la escritora -eterno Narciso entregado a su proyección- sino por lo que revela del público a quien va dirigida esa imagen y de las relaciones de mercado entre escritor y lector. La imagen proyectada es el escritor y también es su máscara: hecha de lo que se es, lo que se busca ser, lo que queda bien que se sea y lo que se sacrifica para ser. Es espejo revelador, pero también puede ser escudo opaco, defensa. Estas consideraciones, válidas para todo escritor, merecen especial atención, creo, en el caso de las mujeres, cuya imagen profesional -me refiero a la producción literaria- es de por sí más fluctuante, menos estereotipada, que la de los hombres" (Molloy, 1983: 15). 
otro espíritu mártir del mismo martirio" (Agustini 2006: 65). La posición subordinada respecto de Darío se percibe en estas palabras:

Acaso su voluntad, más fuerte necesariamente que la mía, no le dejará jamás comprender el sufrimiento de mi debilidad en lucha con tanto horror. [...] Pero si por alguna afinidad mórbida llega usted a percibir mi espíritu, mi verdadero espíritu, en el torbellino de mi locura, me tendría usted la más profunda, la más afectuosa compasión que pueda sentir jamás. (Agustini, 2006: 66)

La desesperación la lleva a pensar en la muerte: "Piense usted que ni aún me queda la esperanza de la muerte, porque la imagino llena de horribles vidas" (Agustini, 2006: 66). A quien Delmira tomará prácticamente como su confesor; tanto es así que Darío no firma con su nombre sino con el de "El Confesor". La correspondencia de Darío junto con la de Ugarte son quizás las de mayor valor del epistolario. No solo por la calidad de la escritura sino porque además en esas cartas abandona las máscaras utilizadas en las cartas con su novio. Si no fuera una afirmación casi imposible de probar, aparece la verdadera o la más auténtica Delmira Agustini, es decir la poeta sufriente.

En el conjunto de emociones del epistolario de la uruguaya, no faltan los celos. Delmira le escribe a Darío que por estar cerca de casarse le ha comentado a su novio que mantendrá correspondencia con el nicaragüense. "Ayer él me pregunta - desliza-, casualmente, si le había escrito si tenía noticias suyas. Me turbé tanto, divagué tanto, que llegó a imaginar lo imposible" (Agustini, 2006: 67). Ella tampoco está excusada de la pasión celosa, le escribe a Reyes en una de las últimas cartas en su particular lenguaje: "Cuando la Nena dabia y lo reta a Quique, es porque está loquita de celos pero no porque dude de su Quique, sino porque tiere mucho, mucho, mucho y le parece siempre que lo va a perder" (Agustini, 2006: 41). En la última carta del epistolario con Reyes, Delmira le comunica ya sin restos de puerilización lo siguiente: "He creído ver en tus ojos una sombra de duda, cuando al darte el retrato te dije que iba solo. Tú dudaste, sí, dudaste, tus palabras de sospecha fueron sinceras. Yo quiero desvanecer esa mala sombra de un momento, yo no quiero que reaparezca en tu alma ni en tus ojos porque a mi también me hiere" (Agustini, 2006: 41). Esas "palabras de sospecha" de Reyes podrían estar vinculadas a ese episodio referido a la 
correspondencia con Darío y aunque no lo fuese, ponen en evidencia que la celotipia podía interponerse entre ellos.

Darío no estará a la altura de las confesiones de Delmira, incluso a sabiendas de que lo son porque en la carta que le responde, Darío firma como "El Confesor"17. En la siguiente carta de Delmira a Darío, ella admite que se trata de confesiones y hasta de un ritual religioso: "Y ahora, la absolución y el olvido. No me conteste a esta carta. Va en el más riguroso secreto de confesión" (Agustini, 2006: 68). A las angustias y pesares de Delmira, Darío solo atina a pedirle: "Tranquilidad, Tranquilidad, [...] Creer sobre todo en una cosa: el Destino. La voluntad misma no está sino sujeta al Destino” (Agustini, 2006: 67).

\section{Conclusiones}

Durante el desarrollo de nuestro trabajo hemos podido reconocer el enorme valor que encierra el epistolario de Delmira Agustini, particularmente en lo que concierne a la economía emocional de la época. Nos hemos ocupado de las cartas que tienen como protagonistas a hombres: su exesposo Enrique Reyes, Manuel Ugarte y Rubén Darío, aunque hay otros corresponsales varones en el epistolario. Sin embargo, existe una triangulación en torno a estos tres hombres: Reyes porque toma una Delmira desde las coordenadas socio-culturales del 900 y normativizada para responder desde ese lugar a los imperativos sociales y familiares; Ugarte lo hace desde una Delmira amante, desde un posicionamiento como mujer deseante, y Rubén Darío como "el confesor" que se asoma a una Delmira sufriente, que da lugar a un "deseo melancolizado".

La lectura densa del epistolario nos permitió desplazarnos a través de dos planos: el textual y el del espesor socio-cultural del Novecientos uruguayo. De ese modo, la escritura epistolar permitió observar la manera

${ }^{17}$ Comenta Silvia Molloy a propósito de este comportamiento de Darío en relación con la condición de mujer y poeta de Agustini: "Acaso sea exagerado ver esta segunda carta de Agustini exclusivamente como respuesta a la somera e indirecta esquela de Darío que la pone - como a las demás mujeres que escriben - 'en su lugar'. Pero que hay conciencia en esa carta del papel que se representa, que ambos representan, me parece claro" (Molloy, 1983: 15). 
como las conductas socialmente codificadas se revelan mediante estrategias a las que Delmira recurre para hacer posible la conversión de experiencia en creación. El epistolario está atravesado por diferentes vectores emocionales que van de la "emoción violenta", movida por el odio (que terminará con la vida de la poeta), a la manifestación de la "pasión amorosa". Dos emociones que pueden proyectarse en el contexto de las sensibilidades del novecientos uruguayo. La reorganización efectuada del epistolario se hizo sobre la base de una lectura que tomó como eje los estados emocionales erótico-amorosos experimentados por Delmira pero también los que la poeta padeció, de acuerdo con las confesiones hechas a Rubén Darío.

Por otra parte, los enigmas que encierran la confrontación de la "Nena" y la poeta. A nuestro juicio, Delmira debe ser tomada para su análisis no solamente desde la vertiente de la personalidad o como persona, tal como lo hizo Arturo Visca (1969), quien nos situó en una dimensión de análisis psicológico (a esta altura superada por la crítica), sino como lo que es: una escritora. Ello nos coloca en el plano de una Delmira como Sujeto de la escritura, lo que implica un más allá de la personalidad, en tanto que como sujeto de la escritura se articula con el deseo y el goce.

\section{Referencias}

Agustini, D. (2006). Cartas de amor. Pról. de Idea Vilariño. Montevideo: Cal y Canto.

Barbagelata, H. (1953). "Evocando el pasado: Dos cartas inéditas de Delmira Agustini”. Cuadernos Americanos, vol. LXXI, set-oct.

Barrán, J., Nahun, B. (1979). El Uruguay del Novecientos. Montevideo: Ediciones de la Banda Oriental.

Bouvet, N. (2006). La escritura epistolar. Buenos Aires: Eudeba.

Bruña Bragado, M. (2014 ). "Mito y realidad en la imagen de la artista:

Delmira Agustini y las variantes de género en la biografía". Alicante: Biblioteca Virtual Miguel de Cervantes. Recuperado de http://www. cervantesvirtual.com/obra/mito-y-realidad-en-la-imagen-de-la-artista-delmira-agustini-y-las-variantes-de-genero-en-la-biografia/

Canfield, M. (2014). "Delmira Agustini o la conciencia del abismo". Re- 
cuperado de http://www.cervantesvirtual.com/obra-visor/delmiraagustini-o-la-conciencia-del-abismo/html/eed162bd-3e4f-4f69-9bda94504557cof2_2.html

Colombi, B. (1999). "En el 900, a orillas del Plata”. Agustini, Delmira. Los cálices vacíos. Edición y prólogo de Beatriz Colombi. Buenos Aires: Simurg. Recuperado de http://www.cervantesvirtual.com/obra-visor/ prologo-a-los-calices-vacios-de-delmira-agustini/html/4daefea3574a-41b4-a107-e6ecb9bf105c_4.html

Delgado, L. (2007). "Reseña”. Giaudrone, Carla. "La degeneración del 900: modelos estético-sexuales de la cultura en el Uruguay del novecientos". Cuadernos Americanos: Nueva Época, Vol. 3, №. 121.

Escaja, T. (2006). "Delmira Agustini, ultimación de un proyecto decadente: El batllismo”. Recuperado de http://www.cervantesvirtual.com/obravisor/delmira-agustini-ultimacion-de-un-proyecto-decadente-el-batllismo/html/503366a3-6d87-4eoe-bd1a-270dco548044_3.html

Fuentes, A. (2010). "La función de la escritura en la experiencia psicoanalítica”. Letras. Revista de Psicoanálisis de la Comunidad de Madrid. Recuperado de http://letraslacanianas.com/index.php/el-pase/14-lafuncion-de-la-escritura-en-la-experiencia-psicoanalitica

García Gutiérrez, R. (2013). “Introducción”. Agustini, D. Los cálices vacíos. Sevilla: Ed. Point de Lunettes.

García Gutiérrez, R. (2016/2017). “Mártir del mismo martirio’: Agustini y Darío". Zama. Buenos Aires.

Giaudrone, C. (2005). La degeneración del 9oo: modelos estéticos-sexuales de la cultura en el Uruguay del 9oo. Montevideo: Ediciones Trilce. Girón Alvarado, J. (1995). Voz poética y máscaras femeninas en la obra de Delmira Agustini. New York: Peter Lang.

Jameson, F. (2002). "Marxismo y posmodernismo". El giro cultural. Escritos seleccionados sobre posmodernismo. Buenos Aires: Manantial.

Jimeno, M. (2004). Crímenes pasionales. Contribución a una antropología de las emociones. Bogotá: Ediciones de la Universidad Nacional de Colombia.

Lara, Alí; Domínguez, Giazú Enciso (2013). "El Giro Afectivo”. Athenea Digital. Revista de Pensamiento e Investigación Social, vol. 13, núm. 3, noviembre, pp. 101-119.

Larre Borges, A. (2006). "Vindicación de Manuel Ugarte. Delmira: un mito 
que siempre vuelve". Agustini, Delmira. Cartas de amor. Pról. de Idea Vilariño. Montevideo: Cal y Canto.

Larre Borges, A. (2014). "El peso del secreto en la correspondencia de Delmira Agustini”. Delmira Agustini en sus papeles. Separata de Lo que los archivos cuentan 3. Montevideo: Biblioteca Nacional. Recuperado de http://www.bibna.gub.uy/innovaportal/file/65602/1/delmiraagustini-en-sus-papeles.pdf

Litvak, L. (1979). Erotismo fin de siglo. Barcelona: Antoni Bosch.

Molloy, S. (1983). "Dos lecturas del cisne: Rubén Darío y Delmira Agustini”. Revista de la Universidad de México, n. 29, set.

Molloy, S. (2017). "La política de la pose". Cuadernos LIRICO, 16.

Parker, D. (1999). "La ley penal y las "leyes caballerescas": hacia el duelo legal en el Uruguay, 1880-1920". En Anuario IEHS, Facultad de Ciencias Humanas, Universidad Nacional del Centro, Tandil-Argentina, $\mathrm{N}^{\circ} 14$.

Pitt-Rivers, J. (1979). Antropología del honor o política de los sexos. Ensayos de antropología mediterránea. Barcelona: Crítica.

Rama, Á. (1991). "Prólogo". Blanco Fombona, Rufino. Diarios de mi vida. Caracas: Monte Ávila.

Real de Azú, C. (1950). "Ambiente espiritual del novecientos”. Número, ene-jun, nros. 6, $7,8$.

Rocca, P. (ed.) (2014). El crimen de Delmira Agustini. Montevideo: Estuario Editora.

Rodríguez Monegal, E. (1950). "La generación del 900”. Número, ene-jun, nros. $6,7,8$.

Rodríguez Monegal, E. (1969). Sexo y poesía en el 900 uruguayo. Los extraños destinos de Roberto y Delmira. Montevideo: Alfa.

Salinas, R. (1996). "La transgresión delictiva de la moral matrimonial y sexual y su represión en Chile tradicional. 1700-1870". Contribuciones Científicas y Tecnológicas, Santiago, $\mathrm{N}^{\circ} 114$, noviembre.

Silva, C. (1968). Genio y figura de Delmira Agustini. Buenos Aires: Editorial Universitaria de Buenos Aires.

Ugarte, M. (1943). "El casamiento de Delmira Agustini”. Mentor, Montevideo, ene.

Ugarte, M. (1947). Escritores iberoamericanos del novecientos. México: Vértice.

Varas, P. (2002). Las máscaras de Delmira Agustini. Montevideo: Vintín. 
Vilariño, I. (2006). "Prólogo". En: Agustini, D. Cartas de amor. Montevideo: Cal y Canto.

Violi, P. (1987). "La intimidad de la ausencia: formas de la estructura epistolar". Revista de Occidente, 68, ene.

Visca, A. (1969). "Prólogo". En: Agustini, Delmira. Correspondencia íntima. Estudio, ordenación y prólogo de Arturo Visca. Montevideo: Biblioteca Nacional.

Visca, A. (1979). "Delmira Agustini: esquema de su itinerario vital y lírico" Recuperado de http://www.cervantesvirtual.com/obra-visor/delmiraagustini-esquema-de-su-itinerario-vital-y-lirico/html/e1fgf8db-1eda415c-9283-820f97ae53cf_2.html\#I_o_ 